\title{
Flucloxacillin: A Review of Characteristics, Properties and Analytical Methods
}

\section{Mariana Nunes de Menezes, Bianca Aparecida de Marco, Flávia Angélica Masquio Fiorentino, Alexander Zimmermann, Ana Carolina Kogawa \& Hérida Regina Nunes Salgado}

To cite this article: Mariana Nunes de Menezes, Bianca Aparecida de Marco, Flávia Angélica Masquio Fiorentino, Alexander Zimmermann, Ana Carolina Kogawa \& Hérida Regina Nunes Salgado (2019) Flucloxacillin: A Review of Characteristics, Properties and Analytical Methods, Critical Reviews in Analytical Chemistry, 49:1, 67-77, DOI: 10.1080/10408347.2018.1468728

To link to this article: https://doi.org/10.1080/10408347.2018.1468728

Published online: 30 May 2018.

Submit your article to this journal $₫$

山ll Article views: 194 


\title{
Flucloxacillin: A Review of Characteristics, Properties and Analytical Methods
}

\author{
Mariana Nunes de Menezes (1Da ${ }^{a}$, Bianca Aparecida de Marco $\mathbb{1}^{b}$, Flávia Angélica Masquio Fiorentino $\mathbb{( D}^{b}$, \\ Alexander Zimmermann ${ }^{c}$, Ana Carolina Kogawa $\mathbb{D}^{\mathrm{b}}$, and Hérida Regina Nunes Salgado (iD) ${ }^{\mathrm{b}}$ \\ aLaboratory of Applied Pharmacology, School of Health Sciences, Pontifícia Universidade Católica do Rio Grande do Sul - PUCRS, Porto Alegre, Brazil; \\ bSão Paulo StateUniversity (UNESP), School of Pharmaceutical Sciences, Campus Araraquara, Araraquara, SP, Brazil; 'Division for Pathobiochemistry, \\ Martin Luther University Halle-Wittenberg, Faculty of Medicine, Institute of Molecular Medicine, Charles-Tanford-Proteinzentrum, Weinberg Campus, \\ Halle, Germany
}

\begin{abstract}
Bacterial resistance is a growing and worrying factor. The high reproducibility of these resistant microorganisms tends to influence the development of new drugs and research related to product quality control. Among the existing antimicrobials, flucloxacillin (FLU) was designed for oral and injectable administration with bactericidal activity. FLU sodium is the form used in pharmaceutical formulations. It is an antimicrobial resistant against penicillinase, an enzyme responsible for cleaving the beta-lactam ring of penicilins, which leads to inactivity of the drug. Qualitative and quantitative analyzes are essential to ensure quality of pharmaceuticals and health of the population. It is important that quality control is effective and appropriate, only then we can win the battle against microbial resistance. In this work, we want to highlight tthe characteristics of FLU as an important antibiotic and methods for the determination of FLU in pharmaceutical products and biological matrices. Among the analytical methods described in the literature for the determination of FLU, high performance liquid chromatography (HPLC) stands out. Anyway, this method uses toxic solvents (e.g. acetonitrile) long columns, which provide long runs, as well as produces large amounts of waste. Currently, the priority changed to develop ecologically correct, conscious and sustainable methods. This new view on analytical methods should be applied to FLU analyzes and used to develop and improve existing methods.
\end{abstract}

\section{KEYWORDS}

Analytical methods;

flucloxacillin; quality control; sustainable method

\section{Introduction}

Increasingly, studies related to antimicrobial agents are intended to contribute to the treatment of infectious diseases and to combating antimicrobial resistance, due to the reproducibility of microorganisms and the development of superbugs. ${ }^{[1,2]}$

Penicillins are broad-spectrum antimicrobial agents and are used for the treatment of numerous infections. They are mainly active against Gram-positive bacteria. ${ }^{[3]}$ Penicillins are classified into several subcategories, which are differentiated by their chemical structures and antimicrobial activities. The effect of flucloxacillin sodium (FLU) in the class of isoxazolepenicillins, which are active penicillins against penicillinase-producing strains, has a molecular chain modification that differentiates its action spectrum. ${ }^{[4]}$

FLU is commonly used for the treatment of serious infections of the skin, soft tissue and the respiratory tractas well as endocarditis and osteomyelitis caused by methicillin susceptible to $S$. aureus. FLU is widely recommended in Europe and Australia for the treatment of staphylococcal infections. In the United Kingdom, FLU is the most commonly prescribed oral antimicrobial for the treatment of staphylococci. ${ }^{[5]}$

In 1970, Sutherland and collaborators ${ }^{[6]}$ showed that FLU was as active as dicloxacillin and oxacillin, and it was slightly more active than cloxacillin. In addition, FLU proved to be effective against penicillin-resistant staphylococci.

Compared to vanomycin FLU is preferred in the treatment of serious diseases produced by resistant bacteria. Due to this important factor, it is extremely relevant to study the main characteristics of the drug, as well as the existing methods in the literature for the identification and/or quantification of this antimicrobial agent. ${ }^{[5]}$

The activities carried out in quality control are certified by the validation of the analytical methods. The equipment as well as the inputs involved in the production process also present quality certification. ${ }^{[7]}$

The study on antimicrobial agents increases the need for the development and production of these drugs, such as FLU, thereby increasing the demand and accountability of the Quality Control (QC) sector for pharmaceutical inputs and finished products in laboratories and industries. Quality control aims to guarantee the quality of the product and ensure the health of the patient. ${ }^{[7]}$

The literature showed varied methods for the evaluation of FLU, such as spectrophotometry in the ultraviolet and visible region, high performance liquid chromatography and coupled to mass spectrometry, capillary electrophoresis and even microbiological method as diffusion in agar. ${ }^{[3,5,8,10,19,20,22,26,31,99]}$

CONTACT Prof. Hérida Regina Nunes Salgado salgadoh@fcfar.unesp.br $=$ Faculdade de Ciências Farmacêuticas, UNESP, Rodovia Araraquara-Jaú, km 1, ZIP 14800-903, Araraquara, SP, Brazil.

Color versions of one or more of the figures in the article can be found online at www.tandfonline.com/batc.

(c) 2018 Taylor \& Francis Group, LLC 
Therefore, the main objective of this review was to identify and analyze the analytical methods described in the literature to FLU. Considering the importance, that flucloxacillin sodium presents in the current antimicrobial treatment. This review showsthe characteristics, properties and highlight the analytical methods for quantification and determination of FLU in both pharmaceutical products and biological samples described in the literature. For this purpose, the search focused on the following databases: PubMed, Scopus and Web of Science whose period ranged from 1977 to 2017.

\section{Flucloxacillin}

Flucloxacillin (FLU) is an antimicrobial that belongs to the semi-synthetic isoxazolpenicillins group. It is an antimicrobial resistant to penicillinase, an enzyme responsible for cleaving the beta-lactam ring, making the other drugs inactive against microorganisms. ${ }^{[8]}$ In this work, we focused on aspects related to form, structural modification, mechanism of action, pharmacodynamics, pharmacokinetics and pharmaceutical properties, as well as methods for FLU analysis are presented below.

\section{Structural form}

There are two forms of flucloxacillin: flucloxacillin sodium (FLU, Figure 1) and flucloxacillin magnesium octahydrate. Flucloxacillin sodium (FLU) is the form used in pharmaceutical formulations. ${ }^{[9,10]}$

\section{Structural Modification}

FLU belongs to the class of semi-synthetic penicillin isoxazole; its structure was modified by the addition of a bulky structure in the lateral group (Figure 2), which acts as a steric hindrance and prevents the approach of betalactamases. The synthesis of FLU is described in patent U.S. 3239307. ${ }^{[1]}$

\section{Mechanism of action}

The mechanisms of action of antimicrobials can act on the interference of cell wall synthesis, inhibition of protein synthesis, interference in DNA synthesis and inhibition of metabolic pathway. ${ }^{[12]}$

FLU inhibits the cell wall biosynthesisofGram positive microorganisms, being a bactericidal drug. The penicillins in general act in this way, preventing the reproduction of bacteria, more specifically inhibiting the synthesis of peptideoglycan, by inhibiting the enzymes transpeptidases. ${ }^{[13]}$ It should be noted that the indiscriminate use of antimicrobials contributes to bacterial resistance, which has become a worldwide health problem. ${ }^{[14]}$

\section{Pharmacokinetics and pharmacodynamics}

FLU is used in the treatment of infectionsof susceptible microorganisms; its bioavailability is $50-70 \%$ after oral administration and its absorption by the intestine is rapid. This drug, can be used orally, intravenously, intramuscularly, intrapleural, intraarticularly and by nebulization. ${ }^{[15,16]}$

FLU is an organic compound, acid in aqueous solution with pKa 2.76 , determined at $37^{\circ} \mathrm{C}$ in $0.15 \mathrm{M} \mathrm{KCl} .^{[17]}$ It has a halflife of approximately 1 hour. FLU can be found in bone tissues, breast milk, pleural and sinuvial fluid; it crosses the placenta and does not diffuse easily in cerebrospinal fluid. ${ }^{[4]}$

\section{Physicochemical properties}

FLU is a semi-synthetic product derived from fermentation, white or almost white, hygroscopic and crystalline. The solubility of FLU is characterized as very soluble in water and methanol, and soluble in ethanol (96\%). The chemical name of FLU is $\quad(2 \mathrm{~S}, 5 \mathrm{R}, 6 \mathrm{R})-6$-[[3-(2-chloro-6-fluorophenyl)-5-methyl-1,2oxazole-4-carbonyl]amino]-3,3-dimethyl-7-oxo-4-thia-1-azabicyclo[3.2.0] heptane-2-carboxylic acid.

Its molecular formula is $\mathrm{C}_{19} \mathrm{H}_{16} \mathrm{ClFN}_{3} \mathrm{NaO}_{5} \mathrm{~S}_{\mathrm{H}} \mathrm{H}_{2} \mathrm{O}$ and molecular weight is $493.869 \mathrm{~mol} / \mathrm{L}^{[10]}$ It has $\operatorname{LogP} 2.58$ and pKa (acid) 3.75. ${ }^{[17]}$

\section{Quality control}

The development of analytical methods for quality control of drugs and pharmaceuticals is a necessity for industries and laboratories. This maintains the excellence of products and the confidence of the consumer. ${ }^{[18]}$

Among the analytical methods for determination and quantification of FLU, there are physical-chemical and microbiological methods, which are presented in Table $1 .^{[19-42]}$

The development of green and eco-friendly methods gained attention over the last yearsin the quality control of drugs; the objective is to develop analytical processes that generate less negative impacts on the environment. ${ }^{[43]}$

\section{Analytical methods for determination and quantification of FLU}

This review provides details about methods of quantification and determination of FLU. Several methods such as high-performance liquid chromatography (LC), high-performance liquid chromatography coupled with mass spectrometry

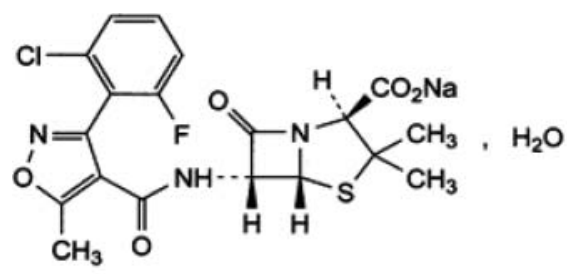

(I)

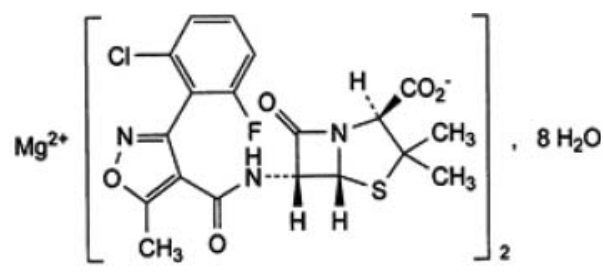

(II)

Figure 1. Chemical structures of flucloxacillin sodium (I) e flucloxacillin magnesium 3 octahydrate (II). 


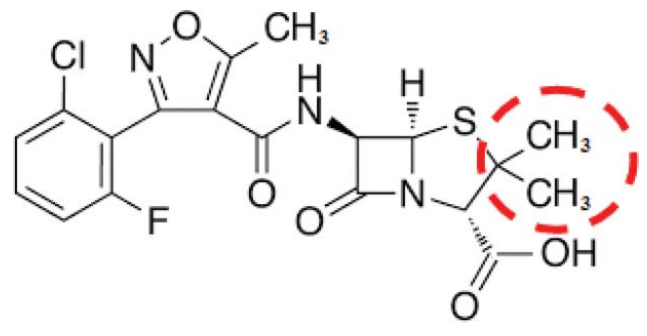

Figure 2. Chemical struture of flucoxacilin (CAS 5250-39-5), focusing the bulky 7 structure.

(LC-MS), spectrophotometry in the ultraviolet and visible regions (UV/ Vis), nuclear magnetic resonance (NMR), gas chromatography (GC), gas chromatography coupled with mass spectrometry (GC-MS), polarography, potentiometry and agar diffusion methods are presented in Table 1.

Determination of the concentration of flucloxacillinin biological fluids or matrices other than blood or urine such as pharmaceutical dosage form may be found in the literature. They range from reference substance, capsules, tablets, oral suspension, and powder for oral suspension to FLU associated with another antimicrobial.Biological samples range from plasma, serum, lymph, urine, skin blister, subcutaneous tissue, muscle to heart valve tissue. ${ }^{[3,10,20,21,26,30,32,40,42,89,91,102,104,108,109]}$

Among the methods for quantification and characterization of FLU, LC stands out in relation to the others, representing $45 \%$ of the total number of methods published in the literature, as shown in Figure 3. Figure 4 shows a graphical representation of the amount of solvents used in the methods of LC and UV for FLU determination described in the current literature.

The information presented is useful for researchers, especially those involved in the development of different dosage forms and for the quality control of FLU and combination with other drugs.

\section{Analytical awareness relevant to $F L U$ analytical methods}

A current approach involves the application of analytical methods with concepts of green chemistry. These methods bring the idea of techniques to be less environmentally aggressive, aiming at the concepts of prevention and sustainability, minimizing the consumption of reagents and energy, as well as the generation of waste in the industry. These are fundamental characteristics to be followed during the development of green and ecofriendly analytical methods. ${ }^{[18,43]}$

Currently, there is an increasing interestrelated to the development of non-aggressive methods to the environment and with low toxicity to the human and animal health. We can cite the principles of green chemistry, where it is essential to execute and ensure that environmentally friendly processes are being carried out. ${ }^{[43,44,47,58-60,85,113]}$ These aspects and principles involve broad improvment of the production, such as prevention of waste generation with planning for the choice of processes, which will avoid waste of products, time and expenses; reduction of the products' toxicities, causing in safety to the operators and environment. The energy demand of chemical processes, that could be minimized with the use of performed under room temperature and pressure conditions to reduce energy expenditure. Analytical methods could be monitored in real time to avoid the formation of hazardous substances in order to considering the minimization of potential accidents, such as leaks, explosions and fires; aiming at greater occupational and environmental safety. ${ }^{[13]}$ New methods and techniques that are able to reduce and eliminate the use and generation of hazardous substances in all stages of chemical analysis are the main objective of the Green Analytical Chemistry (GAC). ${ }^{[4,116]}$ GAC is based mainly on the elimination or minimization of the use of chemical substances, on the minimization of the consumption of electricity, on the correct handling of the generated analytical residues and on the greater safety of the operators. ${ }^{[13]}$

Thus, in general, the methods of analysis for drugs and medicinesare deficient in green, clean and sustainable aspect; therefore, the development of new methods with this new concept has gained space in the laboratories of development of green methods. Moreover, analytical methods play an important role in the pharmaceutical field, being present since the stages of initial drug synthesis until post-marketing steps. ${ }^{[44-48]}$

Gas chromatography is considered greener than liquid chromatography as it does not require solvents for separation. On the other hand, liquid chromatography offers more possibilities of "greening". One alternative is the replacement of toxic solvents with "green" solvents. A green solvent, ethanol for example, is one that offers no risks to the health of the analyst, offers safe handling and biodegradability. It respects the environment, avoiding depletion of ozone and less emission into the air, in addition to involving renewable resources. Production processes, possibility of recycling and cost of energy should also be considered in the evaluation of how a solvent is green. ${ }^{[49,119]}$

In addition to ethanol, other solvents are recommended as isopropyl alcohol, $n$-butanol, ethyl acetate, isopropyl acetate, butyl acetate, anisole, sulfolane and water. ${ }^{[17]}$ Organic solvents should be replaced with water, when possible, or the mixing of organic solvents with water could be considered. However, when this is not possible an alternative is the use of supercritical $\mathrm{CO}_{2}$, which is non-toxic and does not contribute to climate change. Ionic liquids are also a good choice, since they suffer very little evaporation and therefore are not lost to the atmosphere. ${ }^{[118]}$ The analytical techniques can contribute to important information concerning drugs, including the development of new drugs, design of new dosage form and quantification of active content in the commercialized pharmaceutical products. In this aspect, it is important to show pharmacokinetic parameters for therapeutic monitoring of the drug are also related with analytical techniques behavior. ${ }^{[18,50,51]}$

Reviews play an important role in the academic and industrial sector. ${ }^{[114,115]}$ They contribute with relevant informative concerning drugs and pharmaceutical products. ${ }^{[44,45,52-57]}$ Review work, like this one, helps analysts in developing new and better analytical methods because they provide an overview of what already exists in the literature.

In the context of analytical conditions, most of the methods reported in the literature have used water, phosphate buffer, acetonitrile and methanol as mobile phase in isocratic or gradient elution. In our laboratory, researches aim to develop new methods focused in green analytical chemistry such as liquid 


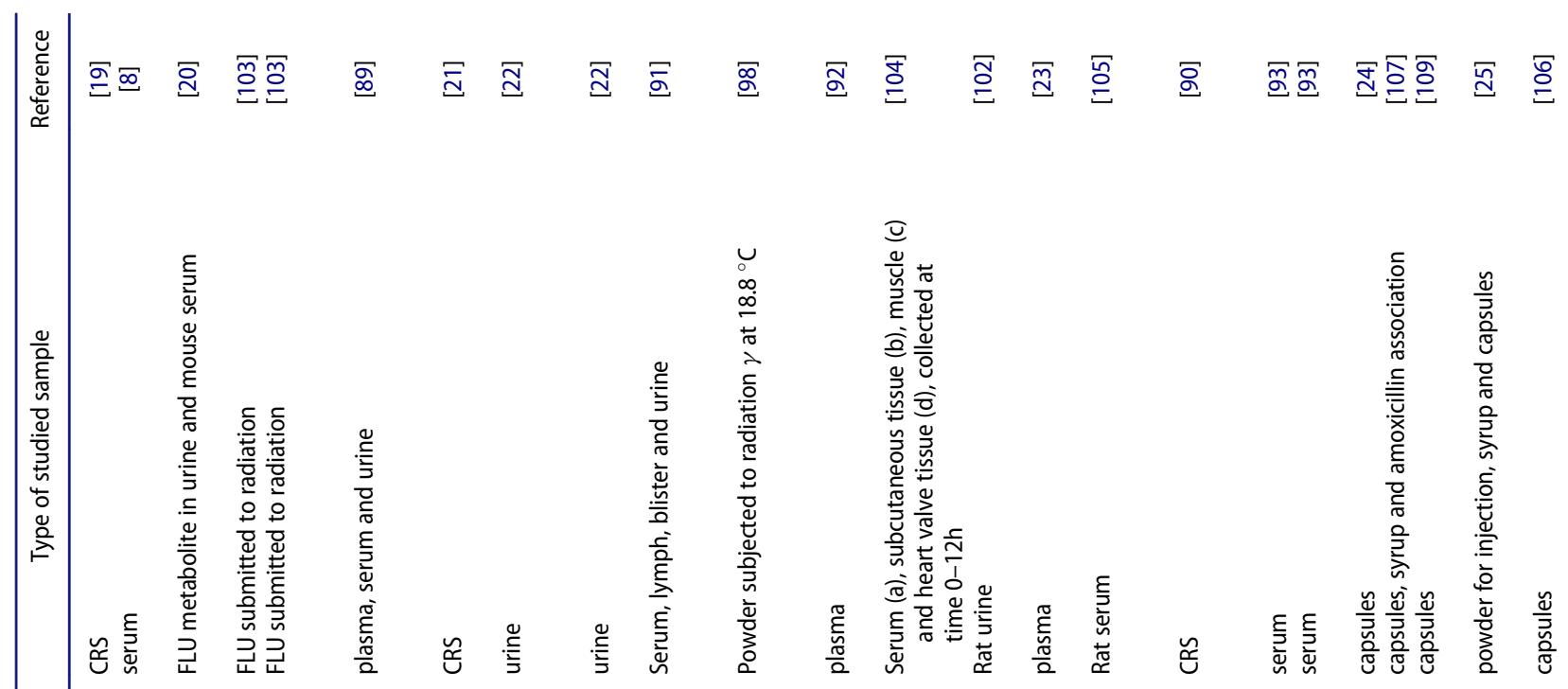

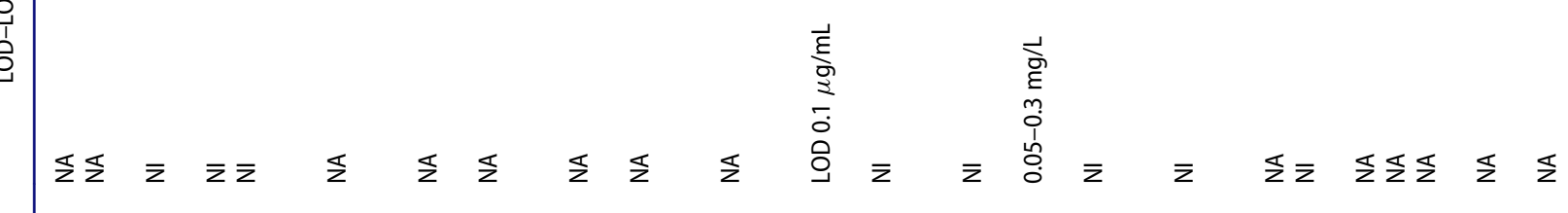

흘

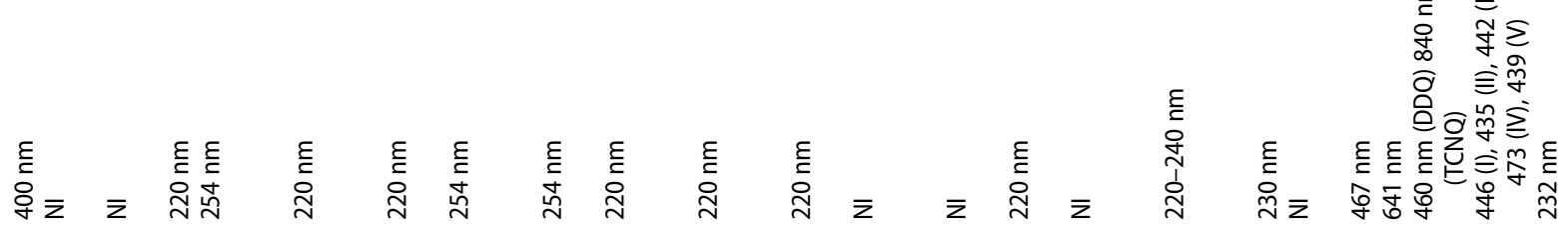

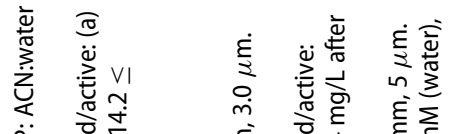
i

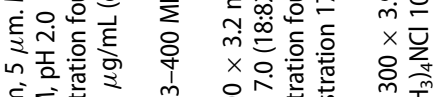
हों हों

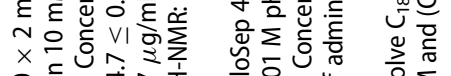

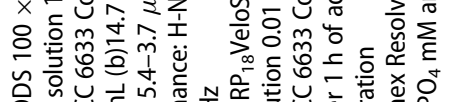

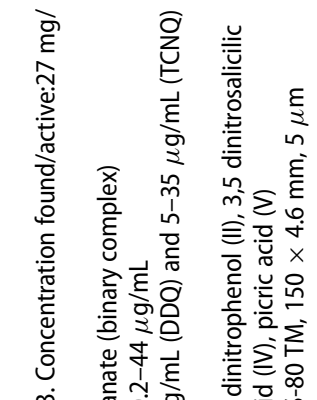

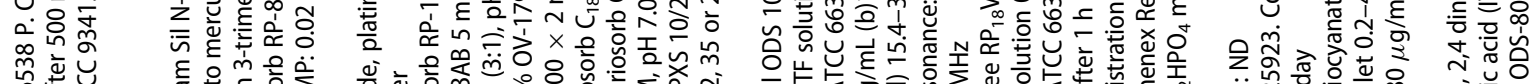

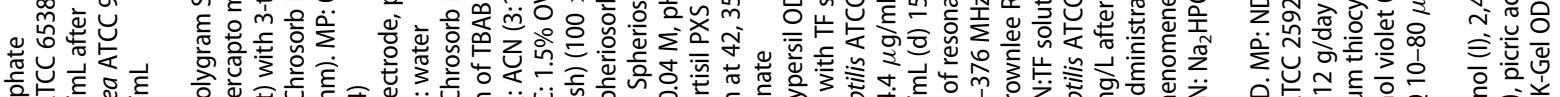

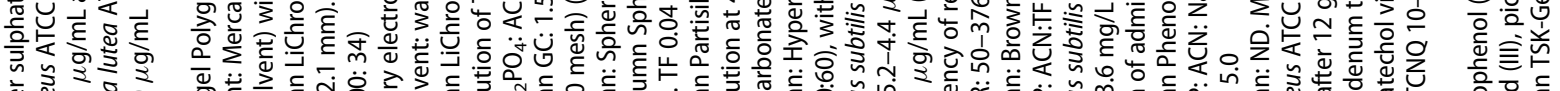

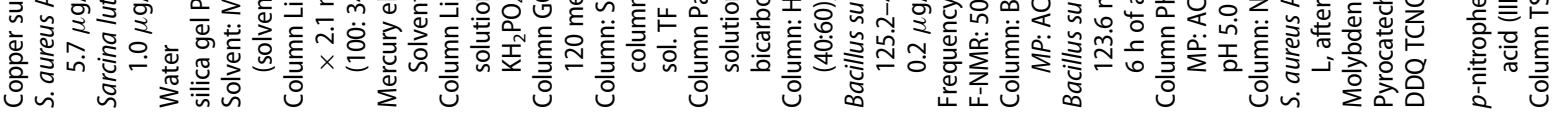

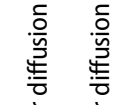
咅

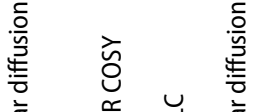
章

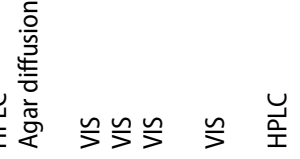




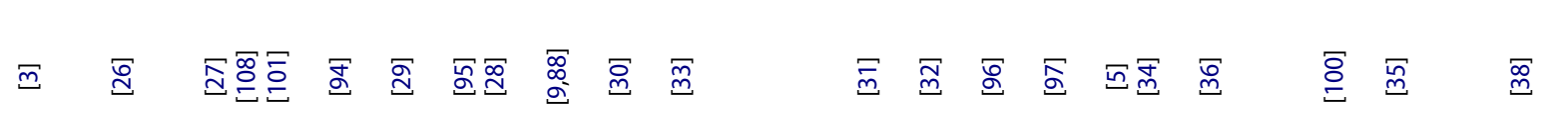
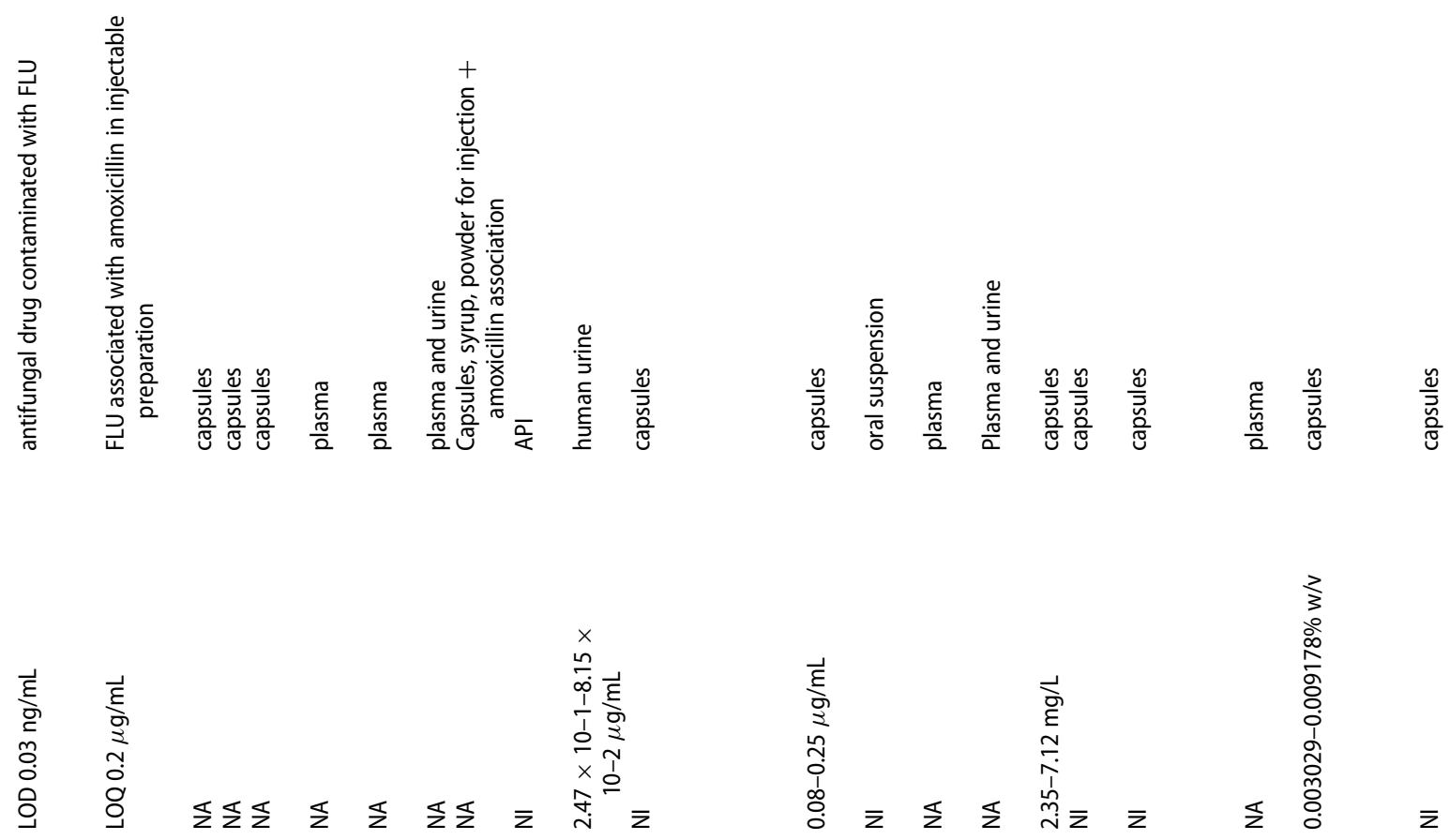

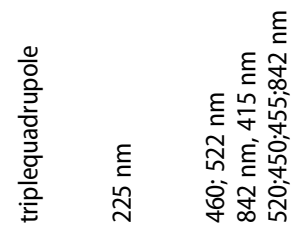

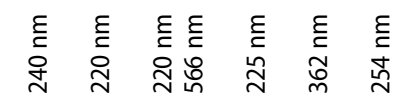

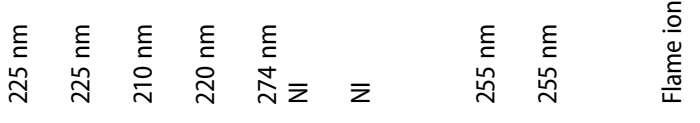

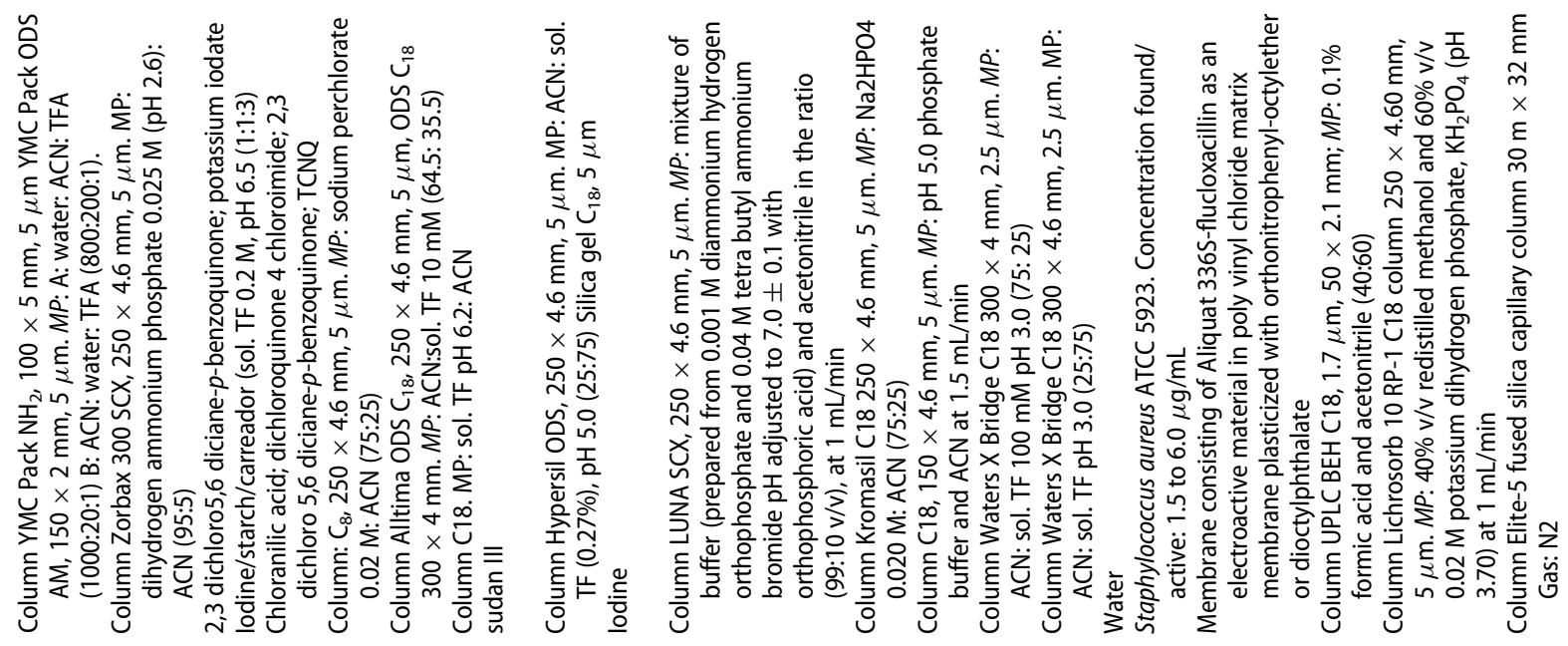




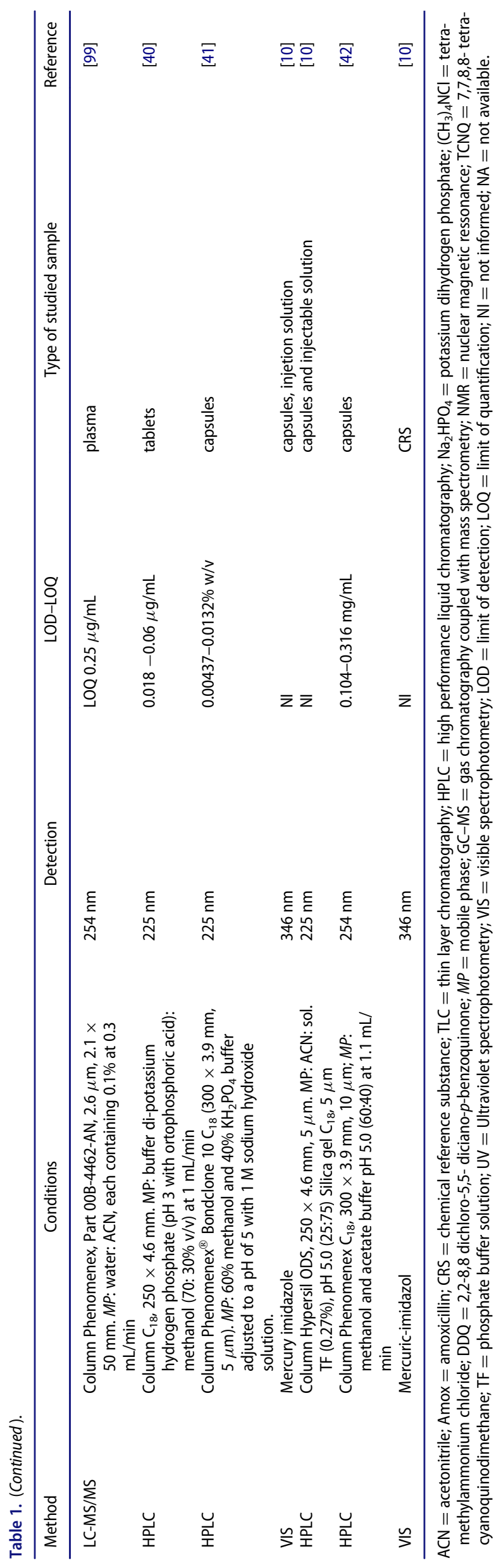




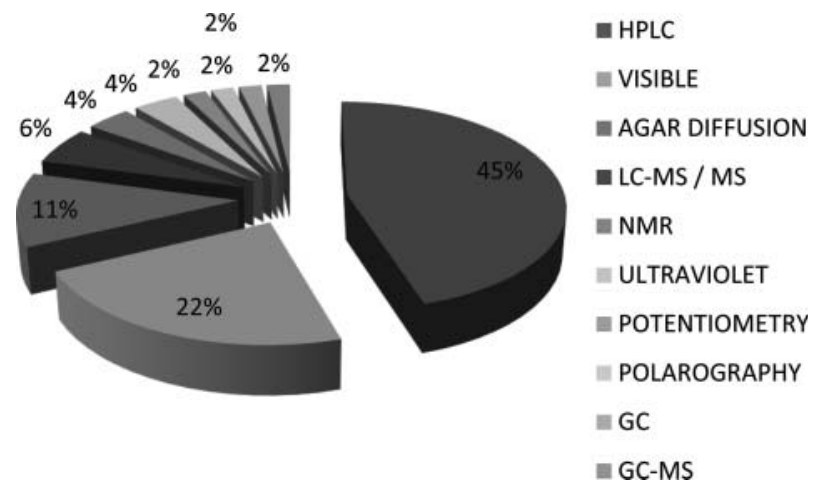

Figure 3. Distribution of analytical methods described in the literature for 2 determination of FLU.

chromatographic techniques using lower toxicity solvent for both environment and human.. ${ }^{[61-84]}$

The HPLC methods for FLU determination still rely on toxic solvents, such as methanol and acetonitrile, ${ }^{[85]}$ and buffer solutions, which reduce the life of the equipment and column, require more cleaning time and therefore more solvents to clean, besides having little time of use, which requires new preparations, and more time for this. ${ }^{[72]}$

Although FLU can be analysed withtitration and spectrophotometric methods that are theoretically inexpensive, simple to perform and quick to release results butthey have disadvantages that put them at the margins of green chemistry and sustainability. Titration requires large quantities of samples, around mg. Spectrophotometric methods in the ultraviolet and visible regions are excellent for routine analyzes, but the used solvent must be carefully chosen because the aliquots used are around $\mathrm{mL}$, while in HPLC and CE are $\mu \mathrm{L}$ and N1. ${ }^{[59,86]}$

Microbiological methods for assessing the potency of FLU as agar diffusion shown in Table 1 are time-consuming and require 20 hours for release of results; in addition to the larger volume of material used. Turbidimetric assay, another type of microbiological method, is more rapid, with results in 4 hours and the evaluationof the results is performed with an spectrophotometric apparatus whereas the evaluation of agar diffusion assay has to be done manually, which can present a higher error or differences from one analyst to another. ${ }^{[56,71,72,76,78,82]}$ However, FLU still lacks this type of innovation.

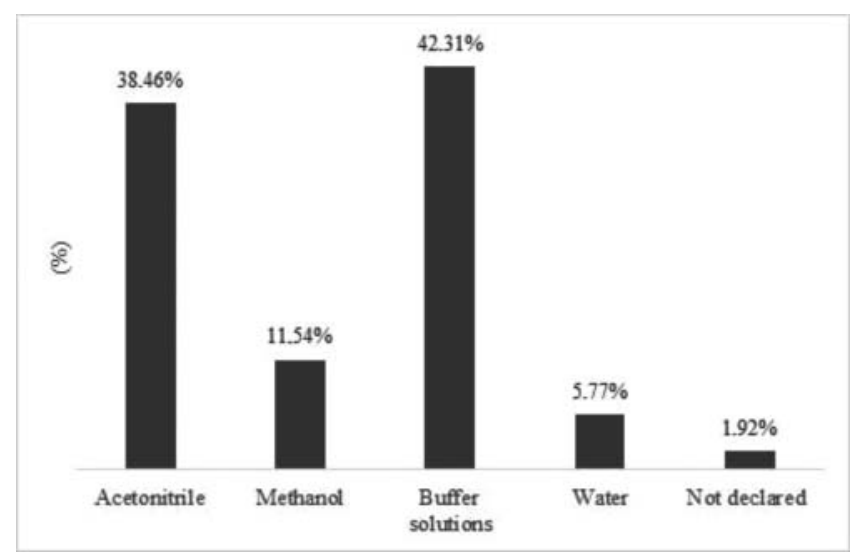

Figure 4. Graphical representation of the amount of solvents used in the methods of $6 \mathrm{HPLC}$ and UV for FLU determination.
Therefore, FLU could have ecologically correct methods and at the same time effective. This is possible and a need of the current pharmaceutical chemistry. Some pharmaceutical products present methods by HPLC using ethanol as solvent and other methods by spectrophotometry in the ultraviolet region using only water as diluents. ${ }^{[81,84,110-112]}$ Perhaps this is the way for green analysis of FLU. Multidimensional thinking is valued nowadays. In addition, analytical methods must to providing reliable results, be fast, low cost and not harmful to the analyst or the environment. The investing in the principles of green analytical chemistry will bring numerous benefits to the environmental, economic and personal future. ${ }^{[113]}$

\section{Conclusion}

Flucloxacillin is a restricted-use antimicrobial indicated for patients with severe and advanced diseases. In Europe and Australia, it is used in the treatment of staphylococcal infections. In the United Kingdom, FLU is the most commonly prescribed oral antimicrobial for the treatment of staphylococci. In Brazil, FLU is still little known, since it was recently included by ANVISA in the List DCB 2005 updated by Resolution 111. ${ }^{[87]}$

The significant consumption of FLU generates the need to develop analytical and bioanalytical methods according to the new reality of the chemical industry for the identification and quantification of FLU, as fast and low cost methods, as well as being neither harmful to the analyst nor to the environment. Among the analytical methods described for the determination of FLU, high performance liquid chromatography stands out, but the methods use toxic solvents, buffer solutions, long columns, which provide long runs and retention times, as well as large amounts of waste. Therefore, the priority to develop ecologically correct, conscious and sustainable methods is very important, current and necessary for the quality control of FLU, optimizing the productivity without harming the environment and the health of the operators. The conclusion must not necessarily choose an ecologically correct class, but analyze the whole set, method, solvents, accessories, time, cost, waste and everything else that involves this analysis.

Antibiotics can save countless lives. Therefore, it is imperative that quality control is effective and appropriate. Only then, we can win the battle against microbial resistance.

\section{Conflict of interest}

The authors declare no conflicts of interest.

\section{Acknowledgments}

The authors acknowledge CNPq (Brasília, Brazil), FAPESP (São Paulo, Brazil) and CAPES (São Paulo, Brazil).

\section{ORCID}

Mariana Nunes de Menezes (iD http://orcid.org/0000-0003-3628-6840 Bianca Aparecida de Marco (iD http://orcid.org/0000-0003-2978-4892 Flávia Angélica Masquio Fiorentino (D) http://orcid.org/0000-0003-10269639

Ana Carolina Kogawa (iD http://orcid.org/0000-0003-2834-6532

Hérida Regina Nunes Salgado (iD http://orcid.org/0000-0002-0385-340X 


\section{References}

[1] Hoefel, H. H. K.; Lautert, L. Administração Endovenosa de antibióticos e Resistência Bacteriana: Responsabilidade da Enfermagem. Rev. Eletrônica Enferm. 2006, 8, 441-449.

[2] Sandle, T. The Antibiotic Crisis and the Need for New Forms of Antibiotics. EC Microbiol. 2014, 1(1), 1-3.

[3] Takada, W.; Adachi, T.; Kihara, N.; Kitamura, S.; Kitagawa, T.; Mifune, M.; Saito, Y. Quantitative Determination Method for Trace Amount of Penicillin Contaminants in Commercially Available Drug Product by HPLC Coupled with Tandem Mass Spectroscopy. Chem. Pharm. Bull. 2005, 53(2), 172-176. doi:10.1248/cpb.53.172.

[4] Martindale: The Complete Drug Reference. 36th. ed. Pharmaceutical Press: London, 2009. p.277.

[5] Fiorentino, F. A. M.; Salgado, H. R. N. Development and Validation of a UV-Spectrophotometric Method for Determination of Flucloxacillin Sodium in Capsules. Curr. Pharm. Anal. 2011, 7, 268-276.

[6] Sutherland, R.; Croydon, E. A. P.; Rolinson, G. N. Flucloxacillin, a New Isoxazolilpenicillin, Compared with Oxacillin, Cloxacillin, and Dicloxacillin. BMJ 1970, 4, 455-460. doi:10.1136/bmj.4.5733.455.

[7] Amorin, S.; Klier, A.; Angelis, L. Quality Control in the Pharmaceutical Industry: Identification of Substances by Infrared Spectroscopy. Rev. Bras. Farm. 2005, 94, 190-198.

[8] Bodey, G. P.; Vallejos, C.; Stewart, D. Flucloxacillin: A New Semisynthetic Isoxazolylpenicillin. Clin. Pharmacol. Ther. 1972, 13, 512-515. doi:10.1002/cpt1972134512.

[9] Portuguese Pharmacopoeia. 8th ed.; Infarmed: Lisboa, 2007.

[10] BP. British Pharmacopeia, The Stationary Office: London, 2017.

[11] Nayler, J. H. C. U.S. 3239307, Beecharn Group Limited: England, 1966.

[12] Acar, J. F. Resistance Mechanisms. Semin. Respir. Infect. 2002, 17 (3), 184-188. doi:10.1053/srin.2002.34690.

[13] Guimaraes, O. D.; Momesso, S. L.; Pupo, T. M. Antibióticos: Importância Terapêutica e Perspectivas Para a Descoberta e Desenvolvimento de Novos Agentes. Química Nova. 2010, 33(3), 667679. doi:10.1590/S0100-40422010000300035.

[14] Queiroz, G. M.; Silva, L. M.; Pietro, R. C. L. R.; Salgado, H. R. N. Multirresistência Microbiana e opções Terapêuticas Disponíveis. Rev. Bras. Clin. Med. São Paulo. 2012, 10(2), 132-138.

[15] Gath, J. C. B.; Sampson, J.; Smithurst, B. Pharmacokinetics and bioavailability of flucloxacillin in elderly hospitalized patients. J. Clin. Pharmacol. 1995, 35, 31-36. doi:10.1002/j.1552-4604.1995.tb04742. $\mathrm{x}$.

[16] PharmaFactz. Pharmacology of Penicillin. Available $<$ http://pharma factz.com/pharmacology-of-penicillin/>. Access on Feb 252018.

[17] Alekseev, V. G. Drug Synthesis Methods and Manufacturing Technology: Acid-base Properties of Penicillins and Cephalosporins (A Review). Pharm. Chem. J. 2010, 44(1), 14-24. doi:10.1007/s11094010-0389-6.

[18] Kogawa, A. C.; Salgado, H. R. N. Analytical Methods Need Optimization to Get Innovative and Continuous Processes for Future Pharmaceuticals. Scholars Acad. J. Pharm. 2016, 5(6), 240-244.

[19] Yasuda, T.; Shimada, S. The Spectrophotometric Determination of 5-metil-3-(2, 6-halogen substituted phenyl)-4-isoxazolyl penicillins (cloxacillin, dicloxacillin and flucloxacillin). J. Antibiot. 1971, 24, 290-293. doi:10.7164/antibiotics.24.290.

[20] Thijssen, H. H. W.; Mattie, H. Active Metabolites of Isoxazolylpenicillins in Humans. Antimicrob. Agents Chemother. 1976, 10(3), 441-446. doi:10.1128/AAC.10.3.441.

[21] Squella, J. A.; Silva, M. M.; Nunez-Vergara, L. J. Anodic Polarographic Determinations of Flucloxacillin. Talanta 1981, 28, 855856. doi:10.1016/0039-9140(81)80030-6.

[22] Murai, Y.; Nakagawa, T.; Yamaoka, K.; Uno, T. High-performance Liquid Chromatographic Determination and Moment Analysis of Urinary Excretion of Flucloxacillin and Its Metabolites in Man. Int. J. Pharm. 1983, 15, 309-320. doi:10.1016/0378-5173(83)90164-3.

[23] Charles, B. G.; Foo, C. C.; Gath, J. Rapid Column Liquid Chromatographic Analysis of Flucloxacillin in Plasma on a Microparticulate Pre-Column. J. Chromatogr. B. 1994, 660, 186-190. doi:10.1016/0378-4347(94)00255-X.
[24] Mohamed, G. G. Spectrophotometric Determination of Ampicillin, Dicloxacillin, Flucloxacillin and Amoxicillin Antibiotic Drug: Ion Pair Formation with Molybdenum and Thiocyanate. J. Pharm. Biomed. Anal. 2001, 24, 561-567. doi:10.1016/S0731-7085(00) 00463-5.

[25] El Mammli, M. Y. Spectrophotometric Determination of Flucloxacillin in Pharmaceutical Preparations using Some Nitrophenols as a Complexing Agent. Spectrochim. Acta Part A 2003, 59, 771-776. doi:10.1016/S1386-1425(02)00237-8.

[26] Liu, H.; Wang, H.; Sunderland, V. B. An Isocratic Ion Exchange HPLC Method for the Simultaneous Determination of Flucloxacillin and Amoxicillin in a Pharmaceutical Formulation for Injection. J. Pharm. Biomed. Anal. 2005, 37, 395-398. doi:10.1016/j. jpba.2004.10.029.

[27] Mohamed, G. G.; El Dien, F. A. N.; Farag, E. U. Spectrophotometric Study of the Reaction Mechanism between ddq as $\pi$ Acceptor and Potassium Iodate and Flucloxacillin and Dicloxacillin Drugs and Their Determination in Pure and in Dosage Forms. Spectrochim. Acta Part A 2006, 65, 11-19. doi:10.1016/j.saa.2005.09.020.

[28] Aly, H.; Mamin, A. S. Utilization of Ion Exchanger and Spectrophotometry for Assaying Amoxycillin and Flucloxacillin in Dosage Form. Int. J. Pharm. 2007, 338, 225-230. doi:10.1016/j. ijpharm.2007.02.012.

[29] Zhou, Q.; Ruan, Z.; Yuan, H.; Jang, B.; Xu, D. RP-HPLC Analysis of Flucloxacillin in Human Plasma: Validation and Application to a Bioequivalence Study. Pharmazie 2007, 62, 101-104.

[30] Gujral, R. S.; Haque, S. M.; Shanker, P. A Sensitive Validated Spectrophotometric Method for the Determination of Flucloxacillin Sodium. E-Journal Chem. 2009, 6, 397-405. doi:10.1155/2009/ 219430.

[31] Nikam, D. S.; Bonde, C. G.; Surana, S. J.; Venkateshwarlu, G.; Dekate, P. G. Development and Validation of RP-HPLC Method for Simultaneous Estimation of Amoxicillin Trihidrate and Flucloxacillin Sodium in Capsule Dosage Form. Int. J. Pharm. Tech. Res. 2009, 1(3), 935-939.

[32] Sankar, D. G.; Rajeswari, A.; Babu, A. N.; Krishna, M. V. RP-HPLC Method for Estimation of Flucloxacillin Magnesium and Sodium Benzoate in Oral Suspension. Asian J. Chem. 2009, 21(8), 58435846.

[33] Shanmugasundaram, P.; Kamal, R. R.; Mohanrangan, J.; Devdass, G.; Arunadevi, M.; Maheswari, R.; Aanandhi, M. V. Simultaneous Estimation of Amoxicillin and Flucloxacillin in Its Combined Capsule Dosage form by HPLC. Rasayam J. Chem. 2009, 2(1), 57-60.

[34] Fiorentino, F. A. M.; Salgado, H. R. N. Development and Validation of a Stability-indicative Agar Diffusion Assay to Determine the Potency of Flucloxacillin Sodium in Capsules. Int. J. Microbiol. Res. 2012, 4(4), 217-222. doi:10.9735/0975-5276.4.4.217-222.

[35] Oppong, M. B. Stability Studies on Flucloxacillin and the Design of an HPLC Method for the Assay of Flucloxacillin in Capsule Dosage Forms. Master, Kwame Nkrumah University of Science and Technology, 2013.

[36] Saber, A. L.; Elmosallamy, M.; Killa, H. M.; Ghoneim, M. M. Selective Potentiometric Method for Determination of Flucloxacillin Antibiotic. J. Taibah Univ. Sci. 2013, 7, 195-201. doi:10.1016/j. jtusci.2013.06.002.

[37] Fiorentino, F. A. M; Sangoi, M. S.; Steppe, M.; Salgado, H. R. N. Development and Validation of a Stability-indicating MEKC Method for Determination of Flucloxacillin Sodium in Capsules. Curr. Anal. Chem. 2014, 10, 149-157. doi:10.2174/ 15734110113099990016.

[38] Haque, S. M. Development and Validation for the Determination of Residual Solvents of Pharmaceutical Formulations of Flucloxacillin Sodium using Head Space Gas Chromatography. Afr. J. Pharm. Pharmacol. 2014, 8(42), 1086-1092.

[39] Larmené-Beld, K. H.; Vries-Koenjer, M. T.; Horst, P. G.; Hospes, W Development and Validation of a Liquid Chromatography/Tandem Mass Spectrometry Method for the Quantification of Flucloxacillin and Cloxacillin in Microdialysis Samples. Biomed. Chromatogr. 2014, 28, 1096-1101. doi:10.1002/bmc.3125. 
[40] Konari, S. N.; Jacob, J. T. Stability-Indicating LC-Analytical Method Development and Validation for the Simultaneous Estimation of Flucloxacillin and Amoxicillin in Pharmaceutical Dosage. F. J. Taibah Univ. Sci. 2015, 9, 167-176. doi:10.1016/j.jtusci.2014.07.005.

[41] Klu, M. W.; Addy, B. S.; Mintah, D. N. A Simple Validated RPHPLC Method for the Analysis of Flucloxacillin Sodium in Capsule Dosage Form. World J. Pharm. Pharmac. Sci. 2016, 5(4), 499-508.

[42] Raymond, A. P. HPLC Method Development for Simultaneous Estimation of Combined Amoxicillin Trihydrate/Flucloxacillin Sodium Capsules. Master, Kwame Nkrumah University of Science and Technology, 2017.

[43] Anastas, P. T. Green Chemistry and the Role of Analytical Methodology Development. Crit. Rev. Anal. Chem. 1999, 29, 167-175. doi:10.1080/10408349891199356.

[44] Lee, D. C.; Webb, M. L. Pharmaceutical Analysis. Blackwell Publishing Ltd: Oxford, 2003.

[45] Hanna-Brown, M. Pharmaceutical Analysis. Anal. Methods. 2012, 4 (6), 1484-1484. doi:10.1039/c2ay90024f.

[46] Marco, B. A.; Salgado, H. R. N. Characteristics, Properties and Analytical Methods of Cefadroxil: A Review. Crit. Rev. Anal. Chem. 2017, 47(2), 93-98. doi:10.1080/10408347.2016.1219649.

[47] Marco, B. A.; Natori, J. S. H.; Fanelli, S.; Tótoli, E. G.; Salgado, H. R. N. Characteristics, Properties and Analytical Methods of Amoxicillin: A Review with Green Approach. Crit. Rev. Anal. Chem. 2017, 47(3), 267-277. doi:10.1080/10408347.2017.1281097.

[48] Sversut, R. A.; Silva, A. A.; Cardoso, T. F. M.; Kassab, N. M.; Amaral, M. S.; Salgado, H. R. N. A Critical Review of Properties and Analytical Methods for the Determination of Oxytetracyline in Biological and Pharmaceutical Matrices. Crit. Rev. Anal. Chem. 2017, 47(2), 154-171. doi:10.1080/10408347.2016.1236673.

[49] Lesellier, E.; West, C. The Many Faces of Packed Column Supercritical Fluid Chromatography - A Critical Review. J. Chromatography A 2015, 1382, 2-46. doi:10.1016/j.chroma.2014.12.083.

[50] Bonfilio, R.; Cazedey, E. C. L.; Araújo, M. B.; Salgado, H. R. N. Analytical Validation of Quantitative High-Performance Liquid Chromatographic Methods in Pharmaceutical Analysis: A Practical Approach. Crit. Rev. Anal. Chem. 2012, 42, 87-100. doi:10.1080/ 10408347.2012.630926.

[51] Tótoli, E. G.; Garg, S.; Salgado, H. R. N. Daptomycin: PhysicoChemical, Analytical and Pharmacological Properties. Ther. Drug Monitor. 2015, 37(6), 699-710. doi:10.1097/ FTD.0000000000000222.

[52] Corrêa, J. C. R.; Salgado, H. R. N. Review of Fluconazole Properties and Analytical Methods for Its Determination. Crit. Rev. Anal. Chem. 2011, 41(2), 124-132. doi:10.1080/10408347.2011.557980.

[53] Magnani, C.; Isaac, V. L. B.; Corrêa, M. A.; Salgado, H. R. N. Caffeic Acid: A Review of Its Potential use for Medications and Cosmetics. Anal. Meth. 2014, 6(10), 3203-3210. doi:10.1039/C3AY41807C.

[54] Chierentin, L.; Salgado, H. R. N. Norfloxacin: A Review of Properties and Analytical Methods. Crit. Rev. Anal. Chem. 2016, 46(1), 22-39. doi:10.1080/10408347.2014.941456.

[55] Consortti, L. P.; Salgado, H. R. N. A Critical Review of Analytical Methods for Quantification of Cefotaxima. Crit. Rev. Anal. Chem. 2017, 47(4), 359-371. doi:10.1080/10408347.2017.1298988.

[56] Curbete, M. M.; Salgado, H. R. N. A Critical Review of Properties of Fusidic Acid and Analytical Methods for Its Determination. Crit. Rev. Anal. Chem. 2016, 46(4), 352-360. doi:10.1080/ 10408347.2015.1084225.

[57] Fernandes, G. F. S.; Salgado, H. R. N.; Santos, J. L. Isoniazid: A Review of Characteristics, Properties and Analytical Methods. Crit. Rev. Anal. Chem. 2017, 47(4), 298-308. doi:10.1080/ 10408347.2017.1281098.

[58] Breslow, R. The Greening of Chemistry. Chem. Eng. News 1996, 26, 72.

[59] Kogawa, A. C.; Salgado, H. R. N. Comparative Study Over Methods Developed for Quantification of Darunavir in Tablets by Environmental Friendly Infrared and Capillary Electrophoretic Techniques. J. Int. Res. Med. Pharm. Sci. 2015, 2, 99-105.

[60] Ravikiran, T. N.; Prasad, Y. R.; Anoop, K. Green Chemistry. World J. Pharm. Pharmac. Sci. 2015, 4, 353-367.
[61] Marona, H. R. N.; Schapoval, E. E. S. A High-Performance Liquid Chromatographic Assay of Sparfloxacin. J. Pharm. Biomed. Anal. 1999, 20, 413-417. doi:10.1016/S0731-7085(98)00102-2.

[62] Marona, H. R. N.; Zuanazzi, J. A. S.; Schapoval, E. E. S. Determination of Sparfloxacin and Its Degradation Products by HPLC-PDA J. Antimicrob. Chemother. 1999, 44(2), 301-302. doi:10.1093/jac/ 44.2.301.

[63] Salgado, H. R. N.; Lopes, C. C. G. O. A High Performance Liquid Chromatographic Assay of Gatifloxacin in Tablets. J. AOAC Int. 2006, 89(3), 642-645.

[64] Tozo, G. C. G.; Salgado, H. R. N. Determination of Lomefloxacin in Raw Material and Tablet Preparations by Liquid Chromatography. J. AOAC Int. 2006, 89(5), 1305-1308.

[65] Moreno, A. H.; Salgado, H. R. N. Development and Validation of HPLC Method for Determination of Ceftazidime. J. AOAC Int. 2008, 91(4), 739-743.

[66] Lopes, C. C. G. O.; Salgado, H. R. N. Development of a Validated Stability-Indicating HPLC Assay and Stress Degradation Studies of Linezolid in Tablets. Chromatographia 2009, 69, 129-133. doi:10.1365/s10337-009-0993-3.

[67] Cazedey, E. C. L.; Perez, D. P.; Perez, J. P.; Salgado, H. R. N. A High Performance Liquid Chromatographic Assay for Ciprofloxacin Hydrochloride Ophthalmic Solution. Chromatographia 2009, 69, 241-244. doi:10.1365/s10337-009-1004-4.

[68] Lopes, C. C. G. O.; Salgado, H. R. N. Performance Characteristics of Bioassay, UV-Spectrophotometry and High Performance Liquid Chromatographic Determination of Gatifloxacin in Tablets. Química Nova 2008, 31(7), 1831-1835. doi:10.1590/S010040422008000700039.

[69] Salgado, H. R. N.; Moreno, A. H.; Garg, S. Development of a New HPLC Method for Determination of Fleroxacin in Bulk and Pharmaceutical Dosage Forms. Chromatographia 2009, 69, 237-240. doi:10.1365/s10337-009-1053-8.

[70] Cazedey, E. C. L.; Othman, A.; Garg, S.; Salgado, H. R. N. A Validated Stability-Indicating LC Method for Orbifloxacin in the Presence of Degradation Products. Curr. Pharm. Anal. 2011, 7(3), 176181. doi:10.2174/157341211796353264.

[71] Vieira, D. C. M.; Salgado, H. R.N. Comparison of HPLC and UV Spectrophotometric Methods for the Determination of Cefuroxime Sodium in Pharmaceutical Products. J. Chromatogr. Sci. 2011, 49, 508-511. doi:10.1093/chrsci/49.7.508.

[72] Kogawa, A. C.; Salgado, H. R.N. Quantification of Doxycycline Hyclate in Tablets by UV-HPLC Method. J. Chromatogr. Sci. 2012, $50,1-7$.

[73] Moreno, A. H.; Salgado, H. R. N. Comparison of High Performance Liquid Chromatography and Three Titrimetric Methods for the Determination of Ceftazidime in Pharmaceutical Formulations. Adv. Anal. Chem. 2012, 2(3), 6-13.

[74] Passoni, M. H.; Salgado, H. R.N. Development and Validation of a New and Rapid HPLC for Determination of Lyophilized Teicoplanin. Anal. Meth. 2012, 4, 1560-1564. doi:10.1039/ C1AY05317E.

[75] Chierentin, L.; Salgado, H. R.N. Development and Validation of a Simple, Rapid and Stability-Indicating High Performance Liquid Chromatography Method for Quantification of Norfloxacin in a Pharmaceutical Product. J. Chromatogr. Sep. Tech. 2013, 4(2), 171175. doi: $10.4172 / 2157-7064.1000171$.

[76] Cazedey, E. C. L.; Salgado, H. R. N. Orbifloxacin. A Review of Properties, Its Antibacterial Activities, Pharmacokinetic/Pharmacodynamic Characteristics, Therapeutic use and Analytical Methods. Crit. Rev. Anal. Chem. 2013, 43(2), 79-99. doi:10.1080/ 10408347.2012.746855.

[77] Silva, L. M.; Salgado, H. R.N. Validation of a Stability-Indicating RP-LC Method for the Determination of Tigecycline in Lyophilized Powder. J. Chromatogr. Sci. 2013, 51(2), 192-199. doi:10.1093/ chromsci/bms126.

[78] Tótoli, E. G.; Salgado, H. R.N. Development and Validation of a Rapid Turbidimetric Assay to Determine the Potency of Ampicillin Sodium in Powder for Dissolution for Injection. Anal. Methods 2013, 5 (21), 5923-5928. doi:10.1039/c3ay40847g. 
[79] Cazedey, E. C. L.; Juodinis, V. D. A.; Salgado, H. R. N. A StabilityIndicating LC Method for Difloxacin in the Presence of Degradation Products. World J. Pharm. Pharmac. Sci. 2014, 3(9), 46-56.

[80] Pedroso, T. M.; Salgado, H. R.N. Validation of Analytical Methodology for Quantification of Cefazolin Sodium by Liquid Chromatography to be Applied for Quality Control in Pharmaceutical Industry. Braz. J. Pharm. Sci. 2014, 50(1), 213-223. doi:10.1590/ S1984-82502011000100022.

[81] Tótoli, E. G.; Salgado, H. R. N. Development and Validation of an Economic, Environmental Friendly and Stability-Indicating Analytical Method for Determination of Ampicillin Sodium for Injection by RP-HPLC. World J. Pharm. Pharmac. Sci. 2014, 3(6), 19281943.

[82] Tótoli, E. G.; Salgado, H. R. N. Development, Optimization and Validation of a Green and Stability-Indicating HPLC Method for Determination of Daptomycin in Lyophilized Powder. J. AOAC Int. 2015, 98(5), 1276-1285. doi:10.5740/jaoacint.15-039.

[83] Pedroso, T. M.; Salgado, H. R. N. A Critical Review of Analytical Methods for Ertapenem Sodium. Crit. Rev. Anal. Chem. 2016, 46 (1), 15-21. doi:10.1080/10408347.2014.937850.

[84] Rodrigues, D. F.; Salgado, H. R. N. Developmentand Validation of a Green Analytical Method of RP-HPLC for Quantification Cefepime Hydrochloride in Pharmaceutical Dosage Forms: Simple, Sensitive and Economic. Curr. Pharm. Anal. 2016, 12(4), 306-314. doi:10.2174/1573412912666151221210921.

[85] McElroy, C. R.; Constantinou, A.; Jones, L. C.; Summerton, L.; Clark, J. H. Towards a Holistic Approach to Metrics for the 21st Century Pharmaceutical Industry. Green Chem. 2015, 17, 31113121. doi:10.1039/C5GC00340G.

[86] Kogawa, A. C.; Aguiar, F. A.; Gaitani, C. M.; Salgado, H. R. N. Validation of a Stability Indicating Capillary Electrophoresis Method for the Determination of Darunavir in Tablets and Comparison with the of Infrared Absorption Spectroscopic Method. World J. Pharm. Pharm. Sci. 2014, 3, 283-297.

[87] Brazil. National Health Surveillance Agency (ANVISA). Instructions for using the List of Brazilian Common Names. http://www.edi toramagister.com/doc_361770_RESOLUCAO_RDC_N_111_ DE_29_DE_ABRIL_DE_2005.aspx. (Accessed Feb 25, 2018).

[88] European Pharmacopoeia. 7th ed. Strasbourg: Council of Europe, 2011.

[89] Thijssen, H. H.W. Analysis of Isoxazolyl Penicillins and Their Metabolites in Body Fluids by High-Performance Liquid Chromatography. J. Chromatogr. 1980, 183, 339-345. doi:10.1016/S03784347(00)81714-4.

[90] Grover, M.; Gulati, M.; Singh, S. Stability-Indicating Analysis of Isoxazolyl Penicillins using Dual Wavelength High-Performance Liquid Chromatography. J. Chromatogr. B 1998, 708, 153-159. doi:10.1016/S0378-4347(97)00654-3.

[91] Bergan, T.; Engeset, A.; Olszewski, W.; Østby, N.; Solberg, R. Extravascular Penetration of Highly Protein-Bound Flucloxacillin. Antimicrob. Agents Chemother. 1986, 30(5), 729-732. doi:10.1128/ AAC.30.5.729.

[92] Hung, C. T.; Lim, J. K. C.; Zoest, A. R. Optimization of High-Performance Liquid Chromatographic Analysis for Isoxazolylpenicillins using Factorial Design. J.Chromatogr. 1988, 425, 331-341. doi:10.1016/0378-4347(88)80037-9.

[93] Leder, K.; Turnidge, J. D.; Korman, T. M.; Grayson, M. L. The Clinical Efficacy of Continuous-Infusion Flucloxacillin in Serious Staphylococcal Sepsis. J. Antimicrob. Chemother. 1999, 43, 113-118. doi:10.1093/jac/43.1.113.

[94] Pullen, J.; Rozario, L.; Stolk, L. M. L.; Degraeuwe, P. L. J.; Van Tiel, F. H.; Zimmermann, L. J. I. Population Pharmacokinetics and Dosing of Flucloxacillin in Preterm and Term Neonates. Ther Drug Monitor. 2006, 28(3), 351-358. doi:10.1097/01. $\mathrm{ftd} .0000211831 .96102 .91$.

[95] Landersdorfer, C. B.; Kikpatrick, C. M. J.; Kinzing-Schippers, M.; Bulitta, J. B.; Holzgrabe, U.; Drusano, G. L.; Sörgel, F. Population Pharmacokinetics at Two Dose Level and Pharmacodynamic Profiling of Flucloxacillin. Antimicrob. Agents Chemother. 2007, 51(9), 3290-3297. doi:10.1128/AAC.01410-06.
[96] McWhinney, B. C.; Wallis, S. C.; Hillister, T.; Roberts, J. A.; Lipman, J.; Ungerer, J. P. J. Analysis of 12 Beta-Lactam Antibiotics in Human Plasma by HPLC with Ultraviolet Detection. J. Chromatogr. B 2010, 878, 2030-2043. doi:10.1016/j.jchromb.2010.05.027.

[97] Ulldemolins, M.; Roberts, J. A.; Wallis, S. C.; Rello, J.; Lipman, J. Flucloxacillin Dosing in Critically Ill Patients with Hypoalbuminaemia: Special Emphasis on Unbound Pharmacokinetics. J. Antimicrob. Chemother. 2010, 65, 1771-1778. doi:10.1093/jac/dkq184.

[98] Jacobs, G. P.; Dobrilovic, L.; Coombes, R.; Raghavan, N. HPLC Analysis of $\gamma$ - irradiated $\beta$-lactam Antibiotics. Int. J. Pharm. 1986, 32, 151-158. doi:10.1016/0378-5173(86)90173-0.

[99] Sime, F. B.; Roberts, M. S.; Roberts, J. A.; Robertson, T.A. Simultaneous Determination of Seven $\beta$-lactam Antibiotics in Human Plasma for Therapeutic Drug Monitoring and Pharmacokinetic Studies. J. Chromatogr. B 2014, 960 (1), 134-144. doi:10.1016/j. jchromb.2014.04.029.

[100] Colin, P.; Bock, L.; T’Jollyn, H.; Boussery, K.; Bocxlaer, J. Development and Validation of a Fast and Uniform Approach to Quantify $\beta$-lactam Antibiotics in Human Plasma by Solid Phase ExtractionLiquid Chromatography-Electrospray-Tandem Mass Spectrometry. Talanta 2013, 103, 285-293. doi:10.1016/j.talanta.2012.10.046.

[101] Refat, M. S.; El-Didamony, A. M. Spectrophotometric and Electrical Studies of Charge Transfer Complexes of Sodium Flucloxacillin with $\pi$ Acceptors. Spectrochim. Acta Part A 2006, 65, 732-741. doi:10.1016/j.saa.2005.12.027.

[102] Everett, J.; Tyler, J.; Woodnutt, G. A. Study of Flucloxacillin Metabolites in Rat Urine by Two-Dimensional 1H, 19F COSY NMR. $J$. Pharm. Biomed. Anal. 1989, 7(3), 397-403. doi:10.1016/0731-7085 (89)80108-6.

[103] Jacobs, G. P. The Radiation-Sterilization of Semi-Synthetic Penicillins. Int. J. Appl. Radiat. Isot. 1979, 30, 417-421. doi:10.1016/0020708X(79)90053-X.

[104] Frank, U.; Schimidt-Eisenlohr, B.; Schlosser, V.; Spillner, G.; Schindler, M; Daschner, F. D. Concentration of Flucloxacillin in Heart Valves and Subcutaneous and Muscle Tissues of Patients Undergoing Open-Heart Surgery. Antimicrob. Agents Chemother. 1988, 32 (6), 930-931. doi:10.1128/AAC.32.6.930.

[105] Entenza, J. M.; Vouillamoz, J.; Glauser, M. P.; Moreillon, P. Levofloxacin Versus Ciprofloxacin, Flucloxacillin, or Vancomycin for Treatment of Experimental Endocarditis Due to Methicillin-Susceptible or Resistant Staphylococcus Aureus. Antimicrob. Agents Chemother. 1997, 4(8), 1662-1667.

[106] El-Gindy, A.; Emara, S.; Hadad, G. M. Determination of Certain Drugs in Binary Mixtures Formulations by Second Derivative Ratio Spectrophotometry and LC. Farmaco 2004, 59, 703-712. doi:10.1016/j.farmac.2004.03.013.

[107] Amin, A. S. Pyrocatechol Violet in Pharmaceutical Analysis. Part I. A Spectrophotometric Method for the Determination of Some $\beta$-lactam Antibiotics in Pure and in Pharmaceutical Dosage Forms. Il Farmaco 2001, 56, 211-218. doi:10.1016/S0014-827X(01)01078-3.

[108] El-Dien, F. N.; Mohamed, G. G.; Farag, E. Y. Z. A. Spectrophotometric Determination of Flucloxacillin and Dicloxacillin in Pure and Dosage Forms. Spectrochim. Acta Mol. Bio. Spectrosc. 2006, 64, 210-215. doi:10.1016/j.saa.2005.06.041.

[109] Al-Ghannam, S. M. New Spectrophotometric Methods for Microdetermination of Fluoxacillin and Cloxacillin in Pure and Dosage Forms. Microchim. Acta 2002, 138, 29-32. doi:10.1007/ s006040200004.

[110] Spagnol, C. M.; Isaac, V. L.; Corrêa, M. A.; Salgado, H. R. N. Validation of HPLC-UV Assay of Caffeic Acid in Emulsions. J. Chromatogr. Sci. 2016, 54, 305-311.

[111] Kogawa, A. C.; Mendonça, J. N.; Lopes, N. P.; Salgado, H. R. N. Method Indicative of Stability for the Determination of Rifaximin and Its Degradation Products by Thin Chromatographyic Method. Curr. Pharm. Anal. 2017, 13, 520-524. doi:10.2174/ 1573412912666160801103712.

[112] Aléssio, P. V.; Kogawa, A. C.; Salgado, H. R. N. Quality of Ceftriaxone Sodium in Lyophilized Powder for Injection Evaluated by Clean, Fast and Efficient Spectrophotometric Method. J. Anal. Meth. Chem. 2017, 2017, 1-4. doi:10.1155/2017/7530242. 
[113] Gałuszka, A.; Migaszewski, Z.; Namieśnik, J. The 12 Principles of Green Analytical Chemistry and the Significance Mnemonic of Green Analytical Practices. Trends Anal. Chem. 2013, 50, 78-84. doi:10.1016/j.trac.2013.04.010.

[114] Siddiqui, M. R.; AlOthman, A. Z.; Rahman, N. Analytical Techniques in Pharmaceutical Analysis: A Review. Arabian J. Chem. 2017, 10, 1409-1421. doi:10.1016/j.arabjc.2013.04.016.

[115] Kogawa, A. C.; Salgado, H. R. N. Analytical Methods: Where do We Stand in the Current Environmental Scenario? EC Microbiology. 2017, 13, 102-104.
[116] Guardia, M. D.; Armenta, S. Green Analytical Methods. Anal. Bioanal. Chem. 2012, 404, 625-626. doi:10.1007/s00216-0126208-z.

[117] Prat, D.; Hayler, J.; Wells, A. A Survey of Solvent Selection Guides. Green Chem. 2014, 16, 4546-4551. doi:10.1039/ C4GC01149J.

[118] Poliakoff, M.; Licence, P. Sustainable Technology: Green Chemistry. Nature. 2007, 450, 810-812. doi:10.1038/450810a.

[119] Salgado, H. R. N. New Analytical Methods for a New Awake Society. EC Microbiology 2017, 9, 39. 